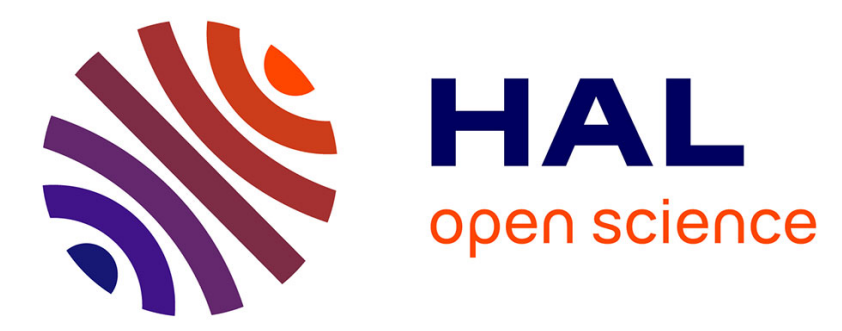

\title{
Modeling the role played by nanoslit lengths on conductance changes into micro nano microfluidics devices
}

Sokhna Mery Ngom, Isabelle Le Potier, Anne-Marie Haghiri-Gosnet, Jean Gamby

\section{To cite this version:}

Sokhna Mery Ngom, Isabelle Le Potier, Anne-Marie Haghiri-Gosnet, Jean Gamby. Modeling the role played by nanoslit lengths on conductance changes into micro nano microfluidics devices. Electrochimica Acta, 2021, 374, pp.137930. 10.1016/j.electacta.2021.137930 . hal-03146574

\author{
HAL Id: hal-03146574 \\ https://hal.science/hal-03146574
}

Submitted on 15 Nov 2021

HAL is a multi-disciplinary open access archive for the deposit and dissemination of scientific research documents, whether they are published or not. The documents may come from teaching and research institutions in France or abroad, or from public or private research centers.
L'archive ouverte pluridisciplinaire HAL, est destinée au dépôt et à la diffusion de documents scientifiques de niveau recherche, publiés ou non, émanant des établissements d'enseignement et de recherche français ou étrangers, des laboratoires publics ou privés. 
Modeling the role played by nanoslit lengths on conductance changes into micro nano microfluidics devices

Sokhna Mery Ngom, ${ }^{1}$ Isabelle Le Potier, ${ }^{1}$ Anne-Marie Haghiri-Gosnet, ${ }^{1}$ and Jean Gamby, $,{ }^{1} \uparrow, *$

${ }^{1}$ Université Paris-Saclay, CNRS, Centre de Nanosciences et de Nanotechnologies, 91120, Palaiseau, France.

$\dagger$ ISE Member

* Corresponding author: jean.gamby@c2n.upsaclay.fr Tel: +33 1702706 70; Fax: +33 1702706 70; 


\begin{abstract}
The aim of this contribution is a better understanding of the conductance changes in nanoslit integrated in microchip device. To this goal voltammetry experiments and modelling were conducted in a hybrid micro nano microchannel (MNM) by taking into account the nanoslit length, the geometry factor influence between the connected microchannels with the main nanoslit, and the background electrolyte concentration. Three models are discussed: (i) a simplified nanochannel conductance model, (ii) a nanochannel conductance model including the role of proton and bicarbonate ionic concentrations on the surface charge state on glass, (iii) a full MNM conductance model including surface and bulk conductance taking into account all the geometric factors for each interface through the MNM device. An eliminating procedure was proposed by subtracting the external microchannels conductances which highlights a net observation of the inverse Duhkin number prediction depending to the nanoslit length. A micromolar concentration zone (from 0.1 $\mu \mathrm{M}$ to $10 \mu \mathrm{M}$ ) is observed where the inverse Duhkin number reaches minimum values around 0.06 and 0.012 for $100 \mu \mathrm{m}$-length and $500 \mu \mathrm{m}$-length nanoslit, respectively. This latter is in agreement with electro-preconcentration protocol of highly diluted analytes in MNM devices where the nanochannel length plays a preeminent role for maximizing enrichment factor.
\end{abstract}

Keywords: nanofluidics; voltammetry; conductance; surface charge; geometric factor; 


\section{Introduction}

The physics of mass transport in solid nanoscale systems is a fast-growing area of research whether it is fundamental or applied. [1],[2],[3],[4],[5],[6],[7],[8],[9],[10] For instance, several applications include the synthesis of nanostructured powders or electrodes as porous materials which offer a large specific area for energy storage [11],[12],[13], but also for the fabrication of nanofluidic devices as a selective and permeable filters to mimic ion channels in biology [14],[15] or as electropreconcentrator devices [16],[17],[18] for sample processing and analysis [19],[20]. For all the mentioned applications, mass transport at nanoscale is affected by nanochannel shape and surface properties. [6],[21],[22],[23] Indeed, in the case of a nanofluidic channel, the role of the surface charge is exacerbated [24],[25] by the liquid confinement between two close solid planes of a few tens of nanometers forming a nanointerface. This nanometric dimension allows new theoretical predictions and experimental discussions beyond the classical microfluidic field [26],[27],[28],[29],[30].

In such a configuration, the predominant parameter governing the physical properties of the interface will be mainly the conductance depending on both the ionic charges and surface charge state. The interfacial charge distribution is generally modeled by the well-known electrical double layer (EDL) comprising two opposite charge regions (the Stern and Diffuse layers). For this purpose, several studies have been devoted to measurements of resistance $(R)$ or conductance $\left(R^{-}\right.$ 1) in micro-nano-microfluidic systems (MNM).

Firstly, we can cite the pioneering work of Stein et al. [26] and Schoch et al. [27] who experimentally evidenced two different regimes depending on the ionic strength of the background electrolyte (BGE). Briefly, at a high ionic strength for an electrolyte 1-1 (typically, $I>10^{-3} \mathrm{M}$ ) for which the Debye length $\left(\lambda_{\mathrm{D}}\right)$ is much smaller than the channel height (typically, $h=50 \mathrm{~nm}$ ), the nanochannel conductance is governed by the overall conductivity of the ionic solution. While for 
a low ionic strength (typically, $I<10^{-4} \mathrm{M}$ ) corresponding to a large length of Debye, the nanochannel conductance becomes independent of the ionic strength and is mainly governed by the surface charge. Moreover, a transition regime with intermediate ionic strength $\left(10^{-4} \mathrm{M}<I<10^{-}\right.$ ${ }^{3} \mathrm{M}$ ) was observed and explained as being an unstable zone (unbalanced between the anionic and cationic species) where the ionic concentration polarization (CP) effects are initiated. This domain was ascribed to the most favorable electro-preconcentration level of highly diluted biomolecules observed by Plecis et al. [31] and Le Louer et al. [32].

Secondly, Reed et al. [29] proposed a revised model including a charge inversion phenomenon based on an effective method of open potential (OP) and conductance measurements. In brief, they compared monovalent 1-1 ion $(\mathrm{NaCl})$ and divalent ion 1-2 $\left(\mathrm{MgCl}_{2}\right)$ electrolytes and observed a strong OP variation associated with an anomalous increase of conductance in the transition zone mainly for the divalent case.

In a more recent work, Green et al [30],[33], revisited the conductance model proposed in the literature for MNM device. They focused their attention on the contribution effects of connected microchannels resistance on the apparent nanochannel resistance which are often disregarded. In brief, they argued that the overall response of a MNM system is determined by the interplay between the nanochannel resistance and the resistances attributed to the microchannels. [33] For this, they proposed a model in which the overall resistance through a MNM device is viewed as a sum of resistances connected in series, i.e. the microchannels, field-focusing, and the nanochannel resistances.

Indeed, as we mentionned previously, several studies already exist on nanochannel conductance but they either involve even unique nanochannel length due to long micro nanofabrication process or time consuming for an experimental characterization [34]. It thus should be interesting to investigate the role played by the nanochannel length and its connected microchannels to 
contribute on the improvement of the models for conductance laws proposed in the literature. A better understanding of the conductance changes in a MNM could allow better theoretical and experimental improvements of the electro-preconcentration phenomenon in this famous intermediate ionic strength range. To this goal, we here propose a measurement methodology using linear cyclic voltammetry (LCV) technique for conductance determination into MNM device. Experiments were conducted in several MNM devices where the nanoslit length varies from 100 $\mu \mathrm{m}$ to $500 \mu \mathrm{m}$. From the obtained experimental results, we propose to test the conductance laws validities by pursuing three different approaches: (i) a simplified nanochannel conductance model, (ii) a nanochannel conductance model including the role of proton and bicarbonate ions within surface charge state on glass, and (iii) a full model MNM conductance model including surface and bulk conductance by taking into account all the geometric factors in the MNM device.

\section{Experimental}

\subsection{Chemicals and reagents}

$\mathrm{NaCl}$ were purchased from Sigma-Aldrich and aqueous solutions were prepared (from $10^{-1} \mathrm{M}$ to $\left.10^{-8} \mathrm{M}\right)$ as background electrolyte in bi-distillated water $(18 \mathrm{M} \Omega)$. Since $\mathrm{NaCl}$ is a monovalent salt, the ionic strength, $I$, is assimilated to ion concentration, $\mathrm{C}$, in this work. The experimental $\mathrm{pH}$ of the solution was measured around $5.8 \pm 0.5$.

\subsection{Nanochannel networks}

The MNM device is presented in Figure 1 and its theoretical dimensions are given in Table 1. The MNM chips used in this work were fabricated in borosilicate glass according to step protocols previously described [32],[35]. In brief, the " $\mathrm{H}$ " shape contains in its center a $150 \mathrm{~nm}$ height 
nanoslit connected with a $1.5 \mu \mathrm{m}$ height microchannel and according to dimensions given in Figure $1 \mathrm{~A}$.

- Figure 1 -

All dimensions of the MNM devices used in this work are listed in table 1 below.

- Table 1-

\subsection{Instrumentation and conductance measurements}

The LCV measurements were performed by using a Biologic Potentiostat (SP 300) coupled with an ultralow current probe which extends current range until $10^{-15} \mathrm{~A}$. This set-up allows to measure low current on high resistive system as in MNM devices. Experiments were performed with a twoelectrode cell configuration. The anode and the cathode were both $\mathrm{Ag} \mid \mathrm{AgCl}$ wires located in the microchannel holes (1) as mentioned in Figure 1. Conductance changes between the two $\mathrm{Ag} \mid \mathrm{AgCl}$ wires are measured by the paths passing through the micro nano microchannels (1-2-3-2-1) or only by the micro microchannels (1-1) in the Figure 1. A procedure was below proposed to deduce conductance through the path (2-3-2) by eliminating the microchannel (1-1) conductance contributions on the overall conductance. The potential range used for LCV measurements was varied from $-1 \mathrm{~V}$ to $1 \mathrm{~V}$ with $10 \mathrm{mV} \mathrm{s}^{-1}$ as scan rate. 


\section{Results and discussion}

\subsection{Conductance measurements}

To measure the global MNM conductance, the following procedure was carried out for various BGE concentrations. The MNM device was first cleaned with bi-distilled water. Then, the lower $\mathrm{NaCl}$ concentration solution $\left(10^{-8} \mathrm{~mol} \mathrm{~L}^{-1}\right)$ was introduced in each reservoir and the chip was quickly filled by capillary motion. Here, only BGE was used to prevent any faradic reaction in the chip. Once the chip was filled a stabilization time over 30 minutes was kept before I/E measurements. All measurements were repeated at least 3-5 times. The same procedure was done for all BGE concentrations, increasing from the lower $\left(10^{-8} \mathrm{~mol} \mathrm{~L}^{-1}\right)$ to the higher concentration $\left(10^{-1} \mathrm{~mol} \mathrm{~L}^{-1}\right)$. A couple of raw data is showing in Figure $2 \mathrm{~A}$ according the $\mathrm{I} / \mathrm{E}$ plot representation, i. e. the measured DC current, I, plotted against the applied potential, E versus $\mathrm{Ag} / \mathrm{AgCl}$ reference electrodes in reservoirs (1-1), as illustrated in Figure 1C. In the case of a symmetrical system where the same ionic concentration are in all microchannel reservoirs on either side of the nanoslit, we assume that the rest potential between the two electrodes is stable. As expected, a purely resistive behaviour was obtained through in a linear variation of the measured current centered at $0 \mathrm{~V}$ (Figure 2A). The obtained experimental conductance curves through "nano" path, $G\left(\mathrm{R}^{-1}\right)$, for a $100 \mu \mathrm{m}$-length nanoslit were plotted with $\mathrm{NaCl}$ concentration (Figure 2B).

- Figure 2 -

The same procedure was carried out by measuring the conductance variation without the nanoslit i.e. only through the external branches "1-1". The unexpected result in Figure $2 \mathrm{~B}$ highlights the same conductance law behavior traditionally obtained for MNM with nanoslit domain. Conversely to several studies in which the restricted domain was supposed to be only responsible to the total 
conductance in MNM conductance, it seems that this is partially or completely wrong depending on the nanoslit or long microchannel dimension (surface/ height ratio aspect) and on the ionic concentrations. According to first observation and explanation in reference [33], there are several geometric factors to consider and to compare in order to assess which parts of the MNM that can be disregarded. To this goal, several approaches were tested from the well-known conductance equation until a proposed form which takes into account all the points previously mentioned.

\subsection{The simplified nanochannel conductance model}

For determining the conductance regime in MNM device, several groups [26], [27], shown that varying the ionic concentrations permitted to highlight two conductance laws which have been clearly identified, as experimentally obtained in Figure 2B. Indeed, in the first simplified approach two main origins of the nanochannel conductance were ascribed to the bulk and the surface conductance, $G_{\mathrm{B}}$ and $G_{\mathrm{S}}$, respectively.

$$
G^{\text {nano }}=G_{B}^{\text {nano }}+G_{S}^{\text {nano }}
$$

$G_{\mathrm{B}}$ is the nanochannel bulk conductance; it varies linearly with the ionic concentration and mobility. $G_{\mathrm{S}}$ is the nanochannel surface conductance i.e. related to surface charges conductivities at vicinity of the solid walls. This layer compensates the solid surface charges (negative ones in this case) containing mainly ions of opposite charges (counterions). The conductance inside this layer is totally different than in bulk solution. The EDL is characterized by the Debye length, $\lambda_{\mathrm{D}}$, which depends on the ionic strength. 
As the height of the nanochannel, $\mathrm{h}_{n}$, is very small (a hundred nanometers), the EDL thickness may become not negligible and affects the total conductance. Indeed, if $\lambda_{\mathrm{D}}<h / 2$, the nanochannel conductance [29],[34],[36], is governed by its bulk conductance expression defined as follows, $G_{B}^{\text {nano }}=F \sum_{i} \mu_{i}[i] h_{n} \frac{\mathrm{w}_{\mathrm{n}}}{\mathrm{L}_{\mathrm{n}}}$

where $\mu_{\mathrm{i}}$ is the ionic mobility, $[i]$ the ionic concentration, $F$, is the Faraday constant, $h_{n}, w_{n}$ and $\mathrm{L}_{\mathrm{n}}$ are respectively the height, width and length of the nanochannel.

Conversely, when $\lambda_{\mathrm{D}}$ is close to $h / 2$, the nanochannel conductance [27] is governed by its surface conductance that is not dependent on the ionic concentration but only on the counterion mobility and on the surface charge, $\sigma_{\mathrm{s}}$. The traditional expression given in the literature [27] is expressed as follows,

$G_{S}^{\text {nano }}=2 \mu_{+} \sigma_{S} \frac{\mathrm{w}_{\mathrm{n}}}{\mathrm{L}_{\mathrm{n}}}$

where $\sigma_{\mathrm{S}}$ here is the glass surface charge.

Finally, Equation (1) can be re-written as the sum of the two contributions $G_{\mathrm{B}}$ and $G_{\mathrm{S}}$ leading to the following Equation (5),

$G_{S}^{\text {nano }}=F \sum_{i} \mu_{i}[i] h_{n} \frac{\mathrm{w}_{\mathrm{n}}}{\mathrm{L}_{\mathrm{n}}}+2 \mu_{+} \sigma_{S} \frac{w_{n}}{\mathrm{~L}_{\mathrm{n}}}$

For preliminary fits, Equation (5) was tested by considering that BGE contains only the cation $\left(\mathrm{Na}^{+}\right)$and the counterion $\left(\mathrm{Cl}^{-}\right)$. Therefore, the four fitted parameters were defined as $\mu_{+}, \mu_{-}, \sigma_{\mathrm{S}}$ and $\mathrm{h}_{\mathrm{n}}$. In first, all parameters were left free then some of them were locked. As expected, the free fitting procedure can leads visually good statistic coefficient of variation $\chi^{2}$, but the channel height and ionic mobility inferred are strongly different from their theoretical values and vary greatly 
depending on the solution studied, whereas they should be the same. For instance, when ionic mobilities were locked to their theoretical values, we obtain no accordance with the experimental curves (See Figures S1 A-B). Conversely, when the nanoslit height and its length are locked, this leads to peculiar values of the surface charge (See Figures S1 C-D). These preliminary fitting results obtained with Equation 5 are shown in Figure S1 and the obtained parameters are listed in Table S1A-B (see the supplementary file). Whatever the nanoslit length that varies from 100 to $500 \mu \mathrm{m}$ with an identical height $h_{\mathrm{n}}$, no match was obtained between the experimental conductance and the fitted parameters with this simplified model (see Equation 5).

\section{Model including the role of proton and bicarbonate on the surface charge state on glass}

Equation (5) does not take into account two main parameters that can influence the nanoslit conductance. First, the distribution of proton and its influence on the nanochannel/liquid interface has often mentioned as being a pH-regulated surface. [8],[22],[36] The proton concentration is defined as follows,

$\left[H^{+}\right]=10^{-p H+3}$ in $\mathrm{mol} \mathrm{m} \mathrm{m}^{-3}$

Second, carbonic acid concentration typically in liquid water at $20^{\circ} \mathrm{C}$ is about $1.2 \times 10^{-5} \mathrm{~mol} \mathrm{~L}^{-1}$. The Equation (7) corresponds to its acid base equilibrium in aqueous solution leading to bicarbonate $\mathrm{HCO}_{3}^{-}$ion, as follows

$\mathrm{H}_{2} \mathrm{CO}_{3} \stackrel{\text { yields }}{\longrightarrow} \mathrm{HCO}_{3}{ }^{-}+\mathrm{H}^{+}$

with the equilibrium constant,

$$
K_{A}=\frac{\left[\mathrm{H}^{+}\right]\left[\mathrm{HCO}^{-}\right]}{\left[\mathrm{H}_{2} \mathrm{CO}_{3}\right]}=10^{-6,37}
$$

which thus determines $\left[\mathrm{HCO}_{3}^{-}\right]=10^{-8,29+p} \quad$ in $\mathrm{mol} \mathrm{m}^{-3}$ 
Finally, to limit the number of free parameters during the fitting procedure, the electroneutrality equation is used to enhance the fitting convergence as follows,

$\left[\mathrm{H}^{+}\right]+\left[\mathrm{Na}^{+}\right]=\left[\mathrm{HCO}_{3}^{-}\right]+\left[\mathrm{Cl}^{-}\right]$

$\left[\mathrm{H}^{+}\right]=10^{-\mathrm{pH}+3}$

$\left[\mathrm{HCO}_{3}^{-}\right]=10^{-8.29+\mathrm{pH}}$

$\left[\mathrm{Na}^{+}\right]=\mathrm{C}$

$\left[\mathrm{Cl}^{-}\right]=\mathrm{C}+10^{-\mathrm{pH}+3}-10^{-8.29+\mathrm{pH}}$

where, $C$ corresponds to the $\mathrm{Na}^{+}$concentration.

Another way to increase the fit quality is also to link the proton influence with the surface conductance $G_{\mathrm{S}}$ as proposed by Ma et al. [36]. Indeed, the main surface charges on the glass substrate are due to its pending chemical functions mainly through the acid base equilibrium (Equation 13) between $\mathrm{SiOH}_{\text {and }} \mathrm{SiO}^{-}$groups at the solid/liquid interface [36],[37], as follows

$$
\begin{aligned}
& \mathrm{SiOH}+\mathrm{H}_{2} \mathrm{O} \Leftrightarrow \mathrm{SiO}^{-}+\mathrm{H}_{3} \mathrm{O}^{+} \quad \text { with } K_{\mathrm{c}}=\frac{\left[\mathrm{SiO}^{-}\right]\left[\mathrm{H}_{3} \mathrm{O}^{+}\right]}{[\mathrm{SiOH}]} \\
& \sigma_{S}=e \cdot \frac{\Gamma_{\mathrm{SiOH}} \cdot 10^{-\mathrm{pKc}}}{10^{-\mathrm{pKc}}+10^{-\mathrm{p}}}
\end{aligned}
$$

with $\Gamma_{\mathrm{SiOH}}$ and $\mathrm{pK}_{\mathrm{c}}$ being the surface site density of $\mathrm{SiOH}$ groups and the equilibrium constant for reaction in Eq. (13), respectively.

Finally, with Equation (15), eight parameters could vary on this new fitting equation i.e. the $\mathrm{pH}$, the $\mathrm{pKc}$, the channel's height, $h_{n}$, the mobilities, $\mu$, the four ions, and the surface site density, $\Gamma_{\mathrm{SiOH}}$. As for the previous model (Equation 5), the physical meaning of the obtained parameters were analyzed from several fitting runs with Equation (15) expressed, as follows

$G^{\text {nano }}=\frac{w_{n}}{L_{n}}\left(\mathrm{~F} \sum_{\mathrm{i}} \mu_{\mathrm{i}}[\mathrm{i}] h_{n}+2 \mu_{+} \mathrm{e} \frac{\Gamma_{\mathrm{SiOH}} 10^{-\mathrm{pKc}}}{10^{-\mathrm{pKc}}+10^{-\mathrm{p}}}\right)$ 
As for the simplified model (Equation 5), all parameters were kept free then the ionic mobilities and/ or the nanochannel height were locked. The fitting results and the obtained parameters are given in Figures S2-3 and listed in Table S2 (see in the supplementary file), respectively.

This improved model shows better agreement between experimental and fitting results than the simplified model. As shown in Table S2, even if the several values seem consistent with the literature, the modelling of the bulk conductance part is not achieved (see Figure S2). Additionally, when the ionic mobilities are kept free (see Figure S3) the fitting curves display very good fit quality but the obtained values (Table S3) have no physical meaning (negative values for some of them).

\subsection{Model including the geometric factor}

As shown in Figure 1A, the MNM device can be divided into 3 domains: the two microchannels (external branches (1)), the lateral microchannels (central branches (2)) and the nanoslit (3), as well as the transition interfaces $((1->2)$ and $(2->3))$. All these domains can be modelled by resistances associated in series (see Figure 3).

- Figure 3 -

As first demonstrated by Green et al. [5],[33], it seems that we cannot clearly neglect the influence of conductance in the external and central branches compared to the apparent conductance measured for nanoslit. The problem is how to take it into account to improve Equation 15. From above Figure 1A and Table 1 showing the "micro" (1-1) or "nano" (1-2-3-2-1) path, and 
dimensions for the external, central branches and nanoslit, the geometric ratios, $r_{1, \mathrm{~m}}, r_{2, \mathrm{~m}}$, and $r_{3, \mathrm{n}}$ , can be defined, respectively as follows,

$r_{1, m}=\frac{2 L_{1, m}}{H_{1} W_{1}}$

$r_{2, m}=\frac{2 L_{2, m}}{H_{2} W_{2}}$

$r_{3, m}=\frac{l_{n}}{h_{n} w_{n}}$

The detailed values of the ratio changes according to the above Equations 16-18 are plotted with the nanoslit length for each MNM device displayed in Figure 4.

- Figure 4

It can be deduced several information from Figure 4. First, the external branches, $r_{1, \mathrm{~m}}$, show a constant ratio (red line) with the nanoslit length. This result is not very surprising since this part of the MNM remains the same. Since this ratio is theoretically constant, it can be mathematically subtracting by an eliminating procedure (vide infra). Second, it can be observed that the influence of the central branches is not negligible. Indeed, conversely to external branches, $r_{2, \mathrm{~m}}$ influence decreases as the nanoslit length increases when two connected central branches length decreases (see Table 1). Third, the influence of the nanoslit length, $r_{3, n}$, is obvious the most important. That is clearly highlighted when the ratios $r_{1, \mathrm{~m}}, r_{2, \mathrm{~m}}$ and $r_{3, \mathrm{n}}$ have close values for a $100 \mu \mathrm{m}$ - nanoslit length, and strongly different for $500 \mu \mathrm{m}$-length, mainly between $r_{2, \mathrm{~m}}$ and $r_{3, \mathrm{n}}$, geometric ratios.

To conclude, Figure 4 underlines the role played by the geometric ratios, where there is a clear difference in behaviour between the lengths 100 and $500 \mu \mathrm{m}$, and permits to better understand why the previous tested models were not fully validated for all nanoslit lengths. 


\subsubsection{First consideration: the role of interfacial resistance}

As shown in Figure 3, MNM device can be simplified into 3 domains (1-2-3) and with two interfaces (1->2 and $2->3)$. The total resistance through the MNM device can be modelled by the sum of resistances in series, as follows

$R=R_{1}+R_{2}+R_{3}+R_{12}+R_{23}$

As we above established with the calculated geometrical factors thanks to the equations (16-18), the higher difference exists between $r_{2, \mathrm{~m}}$ and $r_{3, \mathrm{n}}$ while $r_{1, \mathrm{~m}}$ and $r_{2, \mathrm{~m}}$ are close similar whatever the nanoslit length. Thus, it can be assumed that the interfacial resistance $(1->2)$ can be disregarded while the interfacial resistance (2->3) cannot be. On the basis of these criteria the total resistance can be re-written in the Equation 20, as follows

$$
R^{\text {totale }}=R_{\text {externe }}^{\text {micro }}+R_{\text {centrale }}^{\text {micro }}+R_{\text {interface }}^{\text {micro } / \text { nano }}+\frac{1}{G^{\text {nano }}}
$$

Thus, the total conductance can be written as follows,

$G^{\text {totale }}=\frac{1}{R_{\text {externe }}^{\text {micro }}+R_{\text {centrale }}^{\text {micro }}+R_{\text {interface }}^{\text {micro } / \text { nano }}+\frac{1}{G^{\text {nano }}}}$

or otherwise

$G^{\text {totale }}=G^{\text {nano }} \frac{1}{1+\gamma_{g}}$

with

$\gamma_{g}=G^{\text {nano }}\left(R_{\text {externe }}^{\text {micro }}+R_{\text {centrale }}^{\text {micro }}+R_{\text {interface }}^{\frac{\text { micro }}{\text { nano }}}\right)$ 
In Equation 23, a nondimensionalized number $\gamma_{\mathrm{g}}$ takes into account the influence of both the microchannel resistances (external and central) and interfacial resistance on the measured nanoslit resistance, $G_{\text {nano. }}$.

Finally, after all the above considerations including: proton concentration $(\mathrm{pH})$, ionic mobilities $\left(\mu_{\mathrm{i}}\right)$, the equilibrium constant of glass-water surface reactions $(\mathrm{pKc})$, the height of microchannels $(H)$ or nanoslit $\left(h_{\mathrm{n}}\right)$, and the surface site density of $\mathrm{SiOH}$ groups $\left(\Gamma_{\mathrm{SiOH}}\right)$, Equation $(15)$ is thus adapted by adding a geometric factor $\gamma_{\mathrm{g}}$ to take into account the influence of microchannels and micro/nano interfaces when measurement of conductance in an MNM structure was carried out, as follows

$$
G^{\text {totale }}=\frac{1}{1+\gamma_{g}}\left\{\frac{w_{n}}{L_{n}}\left(\mathrm{~F} \sum_{\mathrm{i}} \mu_{\mathrm{i}}[\mathrm{i}] h_{n}+2 \mu_{+} \mathrm{e} \frac{\Gamma_{\mathrm{SiOH}_{10} 10^{-\mathrm{pKc}}}}{10^{-\mathrm{pKc}+10^{-\mathrm{pH}}}}\right)\right\}
$$

or otherwise

$G^{\text {totale }}=K_{g}\left\{\left(\mathrm{~F} \sum_{\mathrm{i}} \mu_{\mathrm{i}}[\mathrm{i}] h_{n}+2 \mu_{+} \mathrm{e} \frac{\Gamma_{\mathrm{SiOH}} 10^{-\mathrm{pKc}}}{10^{-\mathrm{p}}+10^{-\mathrm{pH}}}\right)\right\}$

with

$K_{g}=\frac{1}{1+\gamma_{g}} \times \frac{w_{n}}{L_{n}}$

From the above Equation (26), it is obvious that $\gamma_{\mathrm{g}}$ is linked to the geometric factor in MNM devices.

\subsubsection{Second consideration: conductance law also in the external microchannel}

As presented in Figure 2.B the overall conductance plots were measured according to the "1-1" path or to "1-2-3-2-3" path where the influence of the external branches can be clearly assessed in accordance with the previous discussion. Now, Equation (25) was tested for all the experimental conductance plots for each "micro" and "nano" path in each MNM device ( $l_{\mathrm{n}}=100 \mu \mathrm{m}$ to $\left.500 \mu \mathrm{m}\right)$. 
The obtained results for 100 and $500 \mu \mathrm{m}$-length were displayed in Figure 5 considering that the "micro" paths for all chips are theoretically the same whatever the used MNM device. As above explained, the ionic mobilities are first locked as well as the heights of the nanoslit and external microchannels $(150 \mathrm{~nm}$ and $1500 \mathrm{~nm})$. Then, the $\mathrm{pKc}$ and $\mathrm{pH}$ were also locked. The resulting fits and its parameters are shown in Table 2. The fits work better and a couple of geometric parameters $\left(h_{\mathrm{n}}, \mathrm{Kg}\right)$, that corresponds better to the experimental curves and takes into account the both heights, i.e. those for the microchannels and the nanoslit, was found. We also note that fitted parameters, $\mu_{\mathrm{i}}, \mathrm{Kc},\left[\mathrm{H}^{+}\right], \Gamma_{\mathrm{SiOH}}$ remain within an expected range, with good statistic coefficient of variation $\chi^{2}$ (see Table 2).

- Figure 5-

- Table 2 -

\subsubsection{Third consideration: Procedure to eliminate external microchannel contribution}

In this last consideration, in view of the evidence that the influence of "1-1" external microchannels within all MNM devices remains constant (see Figure 4), an eliminating procedure is proposed from the "1-1" experimental conductance response in the external branches to the global conductance response. It consists to a linear subtracting of "1-1" conductance from the "12-3-2-1" total conductance before performing the fitting procedure. It therefore remains " $2-3-2$ " conductance that only reflects the two central branches on the conductance connected with the nanoslit (see Figure 1A (insert) and Figure 3). As a serial combination of resistance was considered, the conductance expression used for a linear subtracting is written, as follows,

$$
\frac{1}{G^{\text {totale }}}=\frac{1}{G^{\text {micro }}}+\frac{1}{G^{M N M}}
$$


with $\quad G^{M N M}=\frac{G^{\text {totale }} \times G^{\text {micro }}}{G^{\text {micro }}-G^{\text {totale }}}$

Here, $G^{\text {total }}$ is related to the total measured conductance (external branches, central branches and nanoslit) i.e. "1-2-3-2-1" path, $G^{\text {micro }}$ being the conductance of the external branches, i.e. "1-1" path, and $G^{\mathrm{MNM}}$ is now reduced to the central branches and the nanoslit " $2-3-2$ ".

As the influence of external branches is suppressed, we integrate the central microchannel ratios $\left(w_{\mathrm{n}} / L_{\mathrm{n}}\right)$ for each fit. As a result, the geometric factor $\left(1 / 1+\gamma_{\mathrm{G}}\right)$ can be taken out of the general expression of $K_{\mathrm{g}}$. This final step permits to validate the full model for all nanoslit lengths (from 100 to $500 \mu \mathrm{m})$.

- Table 3 -

- Figure 6 -

\subsubsection{Last consideration: inverse Duhkin number estimation}

The above procedure to determine conductance in MNM devices allowed us to corroborate the influence of connected microchannel with a height 10 -fold higher than the nanoslit. The relatively long lengths could not be neglected in the overall measurement of nanoslit conductance. This intuitive result provides a better understanding of ionic concentration polarization $\mathrm{CP}$ effects [31],[38] in MNM systems where the balance between bulk conductance and surface conductance plays a crucial role. These influences can be predicted by using the inverse Duhkin number, $1 / D_{u}$, that is a nondimensionalized number related to the ratio of bulk conductance to surface conductance, as follows 
$\frac{1}{D u} \approx \frac{G_{B}}{G_{S}}$

As defined by Zangle et. al. [38], [28] on their improved analytical theory of CP, $1 / D_{u}$ is one of the main parameters that govern the mechanisms for ICP of BGE in MNM devices. These theoretical developments were useful in our group to investigate and or predict the influence of BGE on the electro-preconcentration profiles of a diluted analyte during its focusing within nanofluidic in electrophoresis [32],[35].

Here, we proposed to follow the same approach above described where the experimental MNM conductance have been obtained from Equation 28, and now it can be nondimensionalized by the experimental surface conductance, as follows

$\frac{G^{M N M}}{G^{S}}=\frac{G^{B}}{G^{S}}+\frac{G^{S}}{G^{S}} \approx \frac{1}{D u}+1$

or otherwise $\frac{1}{D u} \approx \frac{G^{M N M}}{G^{S}}-1$

- Figure 7-

The plot of $1 / D_{u}$ with the BGE concentration through MNN device is consistent with our experimental results in our recent analytical paper [35] showing that electrokinetic preconcentration of both analytes (fluorescein and ovalbumin) occurs preferentially with BGE low concentration $(10 \mu \mathrm{M} \mathrm{NaCl})$ and it is more efficient within the $500 \mu \mathrm{m}$-length nanoslit rather than $100 \mu \mathrm{m}$-length. As appeared on the read values on Figure 7, lower is the $\mathrm{NaCl}$ concentration, lower is $1 / D_{u}$. Another interesting result is the obtained $1 / D_{u}$ values, where minimum values are reached for $500 \mu \mathrm{m}$-length (around 0.012) and for $100 \mu \mathrm{m}$-length (around 0.06) against BGE 
concentration range from $0.1 \mu \mathrm{M}$ to $10 \mu \mathrm{M}$. Finally, it can be observed that the $1 / D_{u}$ experimental minimum value obtained for $500 \mu \mathrm{m}$-length is 5 -fold lower than the one for $100 \mu \mathrm{m}$-length underlining the role of nanoslit length on $\mathrm{CP}$ effects. This result confirms our previous experimental observation where the CP effect has been found more efficient [35].

However, it can be assumed that regardless the benefit of the nanoslit length increase here highlighted, it is important to stress that the most favorable configuration for maximizing the $\mathrm{CP}$ effect still be a concomitant decrease of the nanoslit height. In order to support this prediction and to validate the effectiveness of the eliminating procedure described previously, simulations in "23-2" configuration were carried out using equations 25 and 28 and parameters listed in Table 3. The procedure followed consisted to decrease the nanoslit height (from $200 \mathrm{~nm}$ to $20 \mathrm{~nm}$ ) and then to increase the nanoslit length (from $100 \mu \mathrm{m}$ to $500 \mu \mathrm{m}$ ). The obtained simulations given in Figures $8 \mathrm{~A}$ and $\mathrm{B}$ underline the shifts on the bulk conductance part and on the transition zone conductance, respectively.

- Figure 8 -

The present model here developed proposes an improved conductance model showing that the length of the nanoslit as well as the influence of the connected microchannels lengths cannot be neglected in the understanding of $\mathrm{CP}$ effects taking place in the concentration zone transition between bulk and surface conductances. It led to a more comprehensive model of conductance modelling by pursuing a stepwise strategy that has the following advantages over those presented in the literature. For instance, we underlined that the well-known nanoslit conductance Equation 5, widely used in the literature [26], [27], proved not entirely satisfactory because it does not account for the influence of length (experimentally increased by a factor of 5). This model has been improved in the literature by taking into account the ionic concentrations and mobilities of 
proton and bicarbonate ions [29] but always with a fixed length. The latter model was also tested in our configuration but by adding a dependence of the surface charge with the electroneutrality equation to link the parameters together (Equations 10-12). Finally, it is a more accurate model for an MNM microdevice which provided consistent results for several lengths. It consists by a determining and then by an eliminating procedures of the contribution of the external microchannels greatly influencing the measurement of the nanoslit conductance. These obtained results enabled us to highlight a net observation of the predictive calculation (1/Du) which confirmed that the directly connected microchannel and nanoslit lengths could not be disregarded in the overall conductance measurement in MNM devices. In perspectives, experimental results of PC effects might be obtained by working in narrower $\left(h_{\mathrm{n}}=20 \mathrm{~nm}\right)$ and longer nanoslits $\left(L_{\mathrm{n}}=500 \mu \mathrm{m}\right)$ as supported by the predictive simulation presented in Figure 8.

\section{Conclusion}

The conductance models in micro nano micro (MNM) device presented in the literature have been revisited by taking into account the role played by the nanoslit length and its connected microchannels. To this goal, three approaches were taken into consideration. First, a simplified model of the nanoslit conductance with only four parameters $\left(\mu_{\mathrm{Na}+}, \mu_{\mathrm{Cl}-}, \mathrm{h}, \sigma_{\mathrm{s}}\right)$ were used to fit the experimental results. Second, an improved model of nanoslit conductance by adding $\mathrm{H}^{+}$and $\mathrm{HCO}_{3}^{-}$ concentrations and their ionic mobilities on the dependence of surface charge conductance was evaluated. The latter improved model having presented limits on the physical meaning of the parameters, in particular on the mobility values, made it necessary to take into account geometric effects. Therefore, full model including the influences of the geometric ratios of the connected 
microchannels (externals, and central branches) within the nanoslit on the total measured MNM conductance was investigated.

Then, an eliminating experimental procedure was carried out to refine the third model by subtracting the contribution of external microchannel conductances. These calculations allowed us to circumvent the MNM conductance measured with around the nanoslit and its directly connected central microchannels and permitted to validate the fitting procedure for the 4 different nanoslit lengths $(100,200,300$ and $500 \mu \mathrm{m})$.

To conclude, a net observation of the predictive inverse Duhkin number plotted with the BGE concentration and the nanoslit length confirms that microchannels with only a height 10 -fold higher than the nanoslit and relatively long lengths could not be neglected in the overall measurement of nanoslit conductance. These results provide a better understanding of ionic concentration polarization $(\mathrm{CP})$ effects in $\mathrm{MNM}$ systems in the range of micromolar BGE concentration (from $0.1 \mu \mathrm{M}$ to $10 \mu \mathrm{M}$ ) where the inverse Duhkin number passes through a minimal value.

\section{Acknowledgments}

This work was supported by the C2N-CNRS technological platform, a member of the RENATECH network.

\section{Credit author statement}

Sokhna Mery Ngom: Investigation, Formal analysis, Visualization. Isabelle Le Potier: Conceptualization, Methodology, Supervision. Anne-Marie Haghiri-Gosnet: Conceptualization, Methodology, Supervision, Resource, Project administration. Jean Gamby: Conceptualization, 
Methodology, Investigation, Formal analysis, Supervision, Visualization, Validation, Writing-

Original draft, Review and Editing.

\section{References}

[1] J.C.T. Eijkel, A. van den Berg, Nanofluidics: what is it and what can we expect from it?, Microfluid. Nanofluid., 1 (2005) 249-267.

[2] J. Cervera, P. Ramirez, S. Mafe, P. Stroeve, Asymmetric nanopore rectification for ion pumping, electrical power generation, and information processing applications, Electrochimica Acta, 56 (2011) 4504-4511.

[3] K. Mathwig, S.G. Lemay, Mass transport in electrochemical nanogap sensors, Electrochimica Acta, 112 (2013) 943-949.

[4] V.V.R. Nandigana, N.R. Aluru, Characterization of electrochemical properties of a micronanochannel integrated system using computational impedance spectroscopy (CIS), Electrochimica Acta, 105 (2013) 514-523.

[5] Y. Green, S. Park, G. Yossifon, Bridging the gap between an isolated nanochannel and a communicating multipore heterogeneous membrane, Physical Review E, 91 (2015) 011002.

[6] S. Qin, D. Liu, G. Wang, D. Portehault, C.J. Garvey, Y. Gogotsi, W. Lei, Y. Chen, High and Stable Ionic Conductivity in 2D Nanofluidic Ion Channels between Boron Nitride Layers, Journal of the American Chemical Society, 139 (2017) 6314-6320.

[7] Y. Xu, B. Lu, L. Fu, J. Zhai, Asymmetric heterostructured SiO2/A12O3 nanofluidic diodes modulating ionic transport for highly efficient light-gating device, Electrochimica Acta, 316 (2019) 266-272.

[8] N. Vilà, P. de Oliveira, A. Walcarius, I.M. Mbomekallé, pH-modulated ion transport and amplified redox response of Keggin-type polyoxometalates through vertically-oriented mesoporous silica nanochannels, Electrochimica Acta, 309 (2019) 209-218.

[9] Y.A. Perez Sirkin, M. Tagliazucchi, I. Szleifer, Transport in nanopores and nanochannels: some fundamental challenges and nature-inspired solutions, Materials Today Advances, 5 (2020) 100047.

[10] L. Bocquet, Nanofluidics coming of age, Nature Materials, 19 (2020) 254-256.

[11] J. Gamby, P.L. Taberna, P. Simon, J.F. Fauvarque, M. Chesneau, Studies and characterisations of various activated carbons used for carbon/carbon supercapacitors, J. Power Sources, 101 (2001) 109-116.

[12] P. Simon, Y. Gogotsi, Charge storage mechanism in nanoporous carbons and its consequence for electrical double layer capacitors, Philosophical Transactions of the Royal Society A: Mathematical, Physical and Engineering Sciences, 368 (2010) 3457-3467.

[13] C. Pean, B. Daffos, B. Rotenberg, P. Levitz, M. Haefele, P.-L. Taberna, P. Simon, M. Salanne, Confinement, Desolvation, And Electrosorption Effects on the Diffusion of Ions in Nanoporous Carbon Electrodes, Journal of the American Chemical Society, 137 (2015) 12627-12632.

[14] B. Yameen, M. Ali, R. Neumann, W. Ensinger, W. Knoll, O. Azzaroni, Synthetic ProtonGated Ion Channels via Single Solid-State Nanochannels Modified with Responsive Polymer Brushes, Nano Letters, 9 (2009) 2788-2793.

[15] S. Marion, A. Radenovic, Towards artificial mechanosensing, Nature Materials, 19 (2020) 1043-1044. 
[16] Y. Wang, K. Pant, Z. Chen, G. Wang, W.F. Diffey, P. Ashley, S. Sundaram, Numerical analysis of electrokinetic transport in micro-nanofluidic interconnect preconcentrator in hydrodynamic flow, Microfluidics and Nanofluidics, 7 (2009) 683.

[17] S.J. Kim, Y.-A. Song, J. Han, Nanofluidic concentration devices for biomolecules utilizing ion concentration polarization: theory, fabrication, and applications, Chemical Society Reviews, 39 (2010) 912-922.

[18] K.-B. Sung, K.-P. Liao, Y.-L. Liu, W.-C. Tian, Development of a nanofluidic preconcentrator with precise sample positioning and multi-channel preconcentration, Microfluidics and Nanofluidics, 14 (2013) 645-655.

[19] X. Xuan, D. Li, Solute separation in nanofluidic channels: pressure-driven or electric fielddriven?, Electrophoresis, 28 (2007) 627-634.

[20] Z. Yuan, A.L. Garcia, G.P. Lopez, D.N. Petsev, Electrokinetic transport and separations in fluidic nanochannels, Electrophoresis, 28 (2007) 595-610.

[21] P. Abgrall, N.T. Nguyen, Nanofluidic Devices and Their Applications, Anal. Chem. (Washington, DC, U. S.), 80 (2008) 2326-2341.

[22] J.-P. Hsu, T.-C. Su, C.-Y. Lin, S. Tseng, Power generation from a pH-regulated nanochannel through reverse electrodialysis: Effects of nanochannel shape and non-uniform $\mathrm{H}+$ distribution, Electrochimica Acta, 294 (2019) 84-92.

[23] K. Froehlich, M. Ali, P. Ramirez, J. Cervera, V. García-Morales, M. Erdmann, W. Ensinger, Effect of cationic polyamidoamine dendrimers on ionic transport through nanochannels, Electrochimica Acta, (2020) 137263.

[24] H.-L. Gao, H. Zhang, C.-Y. Li, X.-H. Xia, Confinement effect of protonation/deprotonation of carboxylic group modified in nanochannel, Electrochimica Acta, 110 (2013) 159-163.

[25] Q. Cao, R.R. Netz, Anomalous electrokinetics at hydrophobic surfaces: Effects of ion specificity and interfacial water structure, Electrochimica Acta, 259 (2018) 1011-1020.

[26] D. Stein, M. Kruithof, C. Dekker, Surface-Charge-Governed Ion Transport in Nanofluidic Channels, Phys. Rev. Lett., 93 (2004) 035901/035901-035901/035904.

[27] R.B. Schoch, H.v. Lintel, P. Renaud, Effect of the surface charge on ion transport through nanoslits, Physics of Fluids, 17 (2005) 100604.

[28] T.A. Zangle, A. Mani, J.G. Santiago, Theory and experiments of concentration polarization and ion focusing at microchannel and nanochannel interfaces, Chemical Society Reviews, 39 (2010) 1014-1035.

[29] S.X. Li, W. Guan, B. Weiner, M.A. Reed, Direct Observation of Charge Inversion in Divalent Nanofluidic Devices, Nano Letters, 15 (2015) 5046-5051.

[30] Y. Green, Current-voltage response for unipolar funnel-shaped nanochannel diodes, Physical Review E, 98 (2018) 033114.

[31] A. Plecis, C. Nanteuil, A.-M. Haghiri-Gosnet, Y. Chen, Electropreconcentration with ChargeSelective Nanochannels, Anal. Chem. (Washington, DC, U. S.), 80 (2008) 9542-9550.

[32] A.-C. Louër, A. Plecis, A. Pallandre, J.-C. Galas, A. Estevez-Torres, A.-M. Haghiri-Gosnet, Pressure-Assisted Selective Preconcentration in a Straight Nanochannel, Analytical Chemistry, 85 (2013) 7948-7956.

[33] Y. Green, R. Eshel, S. Park, G. Yossifon, Interplay between Nanochannel and Microchannel Resistances, Nano Letters, 16 (2016) 2744-2748.

[34] J. Gamby, F.-D. Delapierre, A. Pallandre, B. Tribollet, C. Deslouis, A.-M. Haghiri-Gosnet, Dielectric properties of a single nanochannel investigated by high-frequency impedance spectroscopy, Electrochem. commun., 66 (2016) 5--9. 
[35] S.-M. Ngom, F. Flores-Galicia, F.-D. Delapierre, A. Pallandre, J. Gamby, I. Le Potier, A.-M. Haghiri-Gosnet, Electropreconcentration diagrams to optimize molecular enrichment with low counter pressure in a nanofluidic device, Electrophoresis, 41 (2020) 1617-1626.

[36] Y. Ma, S. Xue, S.-C. Hsu, L.-H. Yeh, S. Qian, H. Tan, Programmable ionic conductance in a pH-regulated gated nanochannel, Physical Chemistry Chemical Physics, 16 (2014) 20138-20146. [37] S.H. Behrens, D.G. Grier, The charge of glass and silica surfaces, The Journal of Chemical Physics, 115 (2001) 6716-6721.

[38] A. Mani, T.A. Zangle, J.G. Santiago, On the Propagation of Concentration Polarization from Microchannel-Nanochannel Interfaces Part I: Analytical Model and Characteristic Analysis, Langmuir, 25 (2009) 3898-3908. 


\section{Tables}

Table 1.

\begin{tabular}{|c|c|c|c|c|c|c|}
\hline Channel & \multicolumn{4}{|c|}{ Length } & Width & Height \\
\hline \multirow{2}{*}{$\begin{array}{l}\text { (1) microchannel } \\
\text { (external) }\end{array}$} & \multicolumn{4}{|c|}{$2 \mathrm{~L}_{1, \mathrm{~m}}(\mu \mathrm{m})$} & $\mathrm{W}_{1}(\mu \mathrm{m})$ & $\mathrm{H}_{1}(\mu \mathrm{m})$ \\
\hline & \multicolumn{4}{|c|}{$2 \times 3489$} & 352.6 & 1.5 \\
\hline \multirow{2}{*}{$\begin{array}{l}\text { (2) microchannel } \\
\text { (central) }\end{array}$} & \multicolumn{4}{|c|}{$2 \mathrm{~L}_{2, \mathrm{~m}}(\mu \mathrm{m})$} & $\mathrm{W}_{2}(\mu \mathrm{m})$ & $\mathrm{H}_{2}(\mu \mathrm{m})$ \\
\hline & $2 \times 780$ & $2 \times 730$ & $2 \times 680$ & $2 \times 580$ & 100 & 1.5 \\
\hline \multirow{2}{*}{ (3) nanoslit } & \multicolumn{4}{|c|}{$l_{n}(\mu \mathrm{m})$} & $w_{n_{-}}(\mu \mathrm{m})$ & $h_{n}(\mathrm{~nm})$ \\
\hline & 100 & 200 & 300 & 500 & 100 & 150 \\
\hline
\end{tabular}

Table 1. Dimensions of the MNM glass device described in Figure 1, where $2 \mathrm{~L}_{1, \mathrm{~m}}, 2 \mathrm{~L}_{2, \mathrm{~m}}$, and $l_{\mathrm{n}}$ being the lengths of the two external branches (1), the two central branches (2), and the nanoslit, respectively. $H_{1}, H_{2}$, and $h_{n}$ being the heights (depths) of the external, the central branches and the nanoslit, respectively. $\mathrm{W}_{1}, \mathrm{~W}_{2}$ and $\mathrm{w}_{\mathrm{n}}$, the widths of the external, the central branches, and the nanoslit, respectively. 
Table 2

\begin{tabular}{|c|c|c|c|c|}
\hline Parameters & $\begin{array}{c}l_{\mathrm{n}}=100 \\
\text { "1-2-3-2-1" }\end{array}$ & $\begin{array}{c}l_{\mathrm{n}}=100 \\
\text { "1-1" }\end{array}$ & $\begin{array}{c}l_{\mathrm{n}}=500 \\
\text { "1-2-3-2-1" }\end{array}$ & $\begin{array}{c}l_{\mathrm{n}}=500 \\
\text { "1-1" }\end{array}$ \\
\hline $\mathrm{pKc}$ & 6.38 & 6.98 & 6.76 & 6.62 \\
\hline $\mathrm{pH}$ & 3.56 & 4.28 & 3.56 & 4.08 \\
\hline $\mathrm{h}_{\mathrm{n}}(\mathrm{m})$ & $1.510^{-07}$ & $1.510^{-06}$ & $1.510^{-07}$ & $1.510^{-06}$ \\
\hline$\mu_{\mathrm{Na}}\left(\mathrm{m}^{2} \mathrm{~V}^{-1} \mathrm{~s}^{-1}\right)$ & $5.8710^{-08}$ & $5.210^{-08}$ & $5.210^{-08}$ & $5.210^{-08}$ \\
\hline$\mu_{\mathrm{Cl}}\left(\mathrm{m}^{2} \mathrm{~V}^{-1} \mathrm{~s}^{-1}\right)$ & $7.9110^{-08}$ & $7.9110^{-08}$ & $7.9110^{-08}$ & $7.9110^{-08}$ \\
\hline$\mu_{\mathrm{H}}\left(\mathrm{m}^{2} \mathrm{~V}^{-1} \mathrm{~s}^{-1}\right)$ & $4.7510^{-07}$ & $3.6310^{-07}$ & $3.6310^{-07}$ & $3.6310^{-07}$ \\
\hline$\mu_{\mathrm{HCO} 3}\left(\mathrm{~m}^{2} \mathrm{~V}^{-1} \mathrm{~s}^{-1}\right)$ & $3.3510^{-08}$ & $4.6510^{-08}$ & $4.6510^{-08}$ & $4.6510^{-08}$ \\
\hline$\Gamma_{\mathrm{SiOH}}\left(\mathrm{m}^{-2}\right)$ & $1.210^{+18}$ & $7.9510^{+18}$ & $8.1510^{+18}$ & $8.5510^{+18}$ \\
\hline $\mathrm{Kg}$ & 0.046 & 0.028 & 0.031 & 0.016 \\
\hline$\chi^{2}$ & 0.023 & 0.078 & 0.097 & 0.051 \\
\hline
\end{tabular}

Table 2. Values determined for the fitted parameters using Equation (25) for all MNM devices whatever their dimensions (see Table 1). 
Table 3

\begin{tabular}{|c|c|c|c|c|}
\hline parameters & $\begin{array}{c}l_{\mathrm{n}}=100 \\
\text { "2-3-2" }\end{array}$ & $\begin{array}{c}l_{\mathrm{n}}=200 \\
\text { "2-3-2" }\end{array}$ & $\begin{array}{c}l_{\mathrm{n}}=300 \\
\text { "2-3-2" }\end{array}$ & $\begin{array}{c}l_{\mathrm{n}}=500 \\
\text { "2-3-2" }\end{array}$ \\
\hline $\mathrm{pKc}$ & 6.27 & 6.89 & 7.41 & 6.23 \\
\hline $\mathrm{pH}$ & 4.43 & 4.56 & 5.25 & 4.56 \\
\hline $\mathrm{h}_{\mathrm{n}}(\mathrm{m})$ & $1.510^{-07}$ & $1.510^{-07}$ & $1.510^{-07}$ & $1.510^{-07}$ \\
\hline$\mu_{\mathrm{Na}}\left(\mathrm{m}^{2} \mathrm{~V}^{-1} \mathrm{~s}^{-1}\right)$ & $5.8710^{-08}$ & $1.0910^{-07}$ & $210^{-07}$ & $1.0910^{-07}$ \\
\hline$\mu_{\mathrm{Cl}}\left(\mathrm{m}^{2} \mathrm{~V}^{-1} \mathrm{~s}^{-1}\right)$ & $7.9110^{-08}$ & $7.2910^{-08}$ & $3.2510^{-08}$ & $7.2910^{-08}$ \\
\hline$\mu_{\mathrm{H}}\left(\mathrm{m}^{2} \mathrm{~V}^{-1} \mathrm{~s}^{-1}\right)$ & $4.7610^{-08}$ & $1.3510^{-07}$ & $2.1310^{-07}$ & $1.3510^{-07}$ \\
\hline$\mu_{\mathrm{HCO} 3}\left(\mathrm{~m}^{2} \mathrm{~V}^{-1} \mathrm{~s}^{-1}\right)$ & $3.35710^{-08}$ & $3.3510^{-08}$ & $3.3510^{-08}$ & $3.3510^{-08}$ \\
\hline$\Gamma_{\mathrm{SiOH}}\left(\mathrm{m}^{-2}\right)$ & $8.010^{+18}$ & $6.010^{+18}$ & $6.010^{+18}$ & $6.7810^{+18}$ \\
\hline $\mathrm{W}_{\mathrm{n}}(\mathrm{m})$ & 0.0001 & 0.0001 & 0.0001 & 0.0001 \\
\hline $\mathrm{L}_{\mathrm{n}}(\mathrm{m})$ & 0.0001 & 0.0002 & 0.0003 & 0.0005 \\
\hline$\left(1 / 1+\gamma_{\mathrm{G}}\right)$ & 0.0874 & 0.196 & 0.201 & 0.133 \\
\hline$\chi^{2}$ & 0.039 & 0.15 & 0.14 & 0.12 \\
\hline
\end{tabular}

Table 3. Values determined for the fitted parameters using Equations 26, 27 and 28 for all MNM device after the eliminating procedure of the contribution of the external branches "1-1" (see Figure 6). 


\section{Figures}

\section{Figure 1}

A

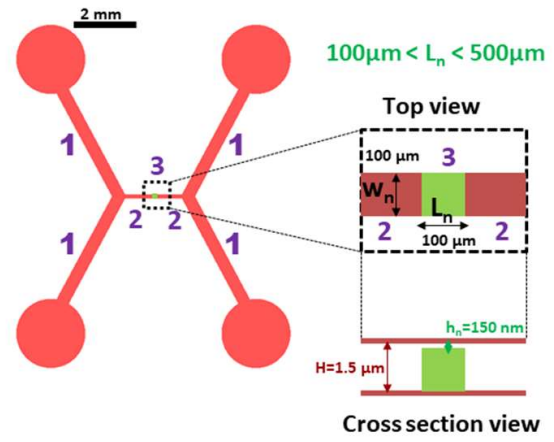

B

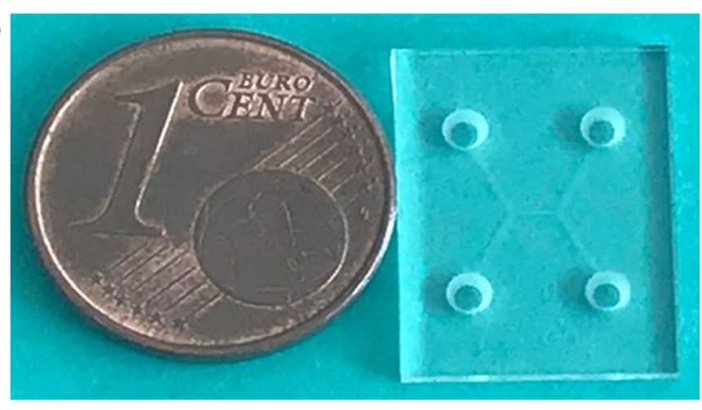

Micro path

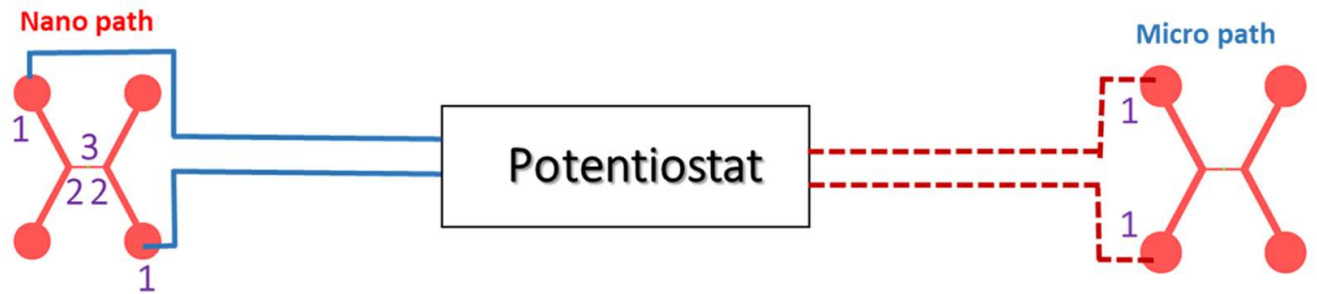

Figure 1. A. MNM chip geometry designed using L-Edit software. At each corner, four microchannel holes (1) are used for electrolyte introduction. The microchannel (2) is reduced to nanometric size on a short distance (see nanofabrication protocol) to obtain the nanochannel (3) in the middle $\left(\mathrm{L}_{\mathrm{n}}=100 \mu \mathrm{m} ; \mathrm{Wn}=100 \mu \mathrm{m}, \mathrm{H}=1.5 \mu \mathrm{m}, \mathrm{h}_{\mathrm{n}}=\right.$ $150 \mathrm{~nm})$. B. Photography of final MNM device. C. Schematic representation of the experimental set-up for voltammetric measurements. The "nano path" corresponds to the path (1-2-3-2-1) that current lines passes through the nanoslit (3), while the "micro path" corresponds to the path (1-1) through only the microchannels (1-1). 


\section{Figure 2}
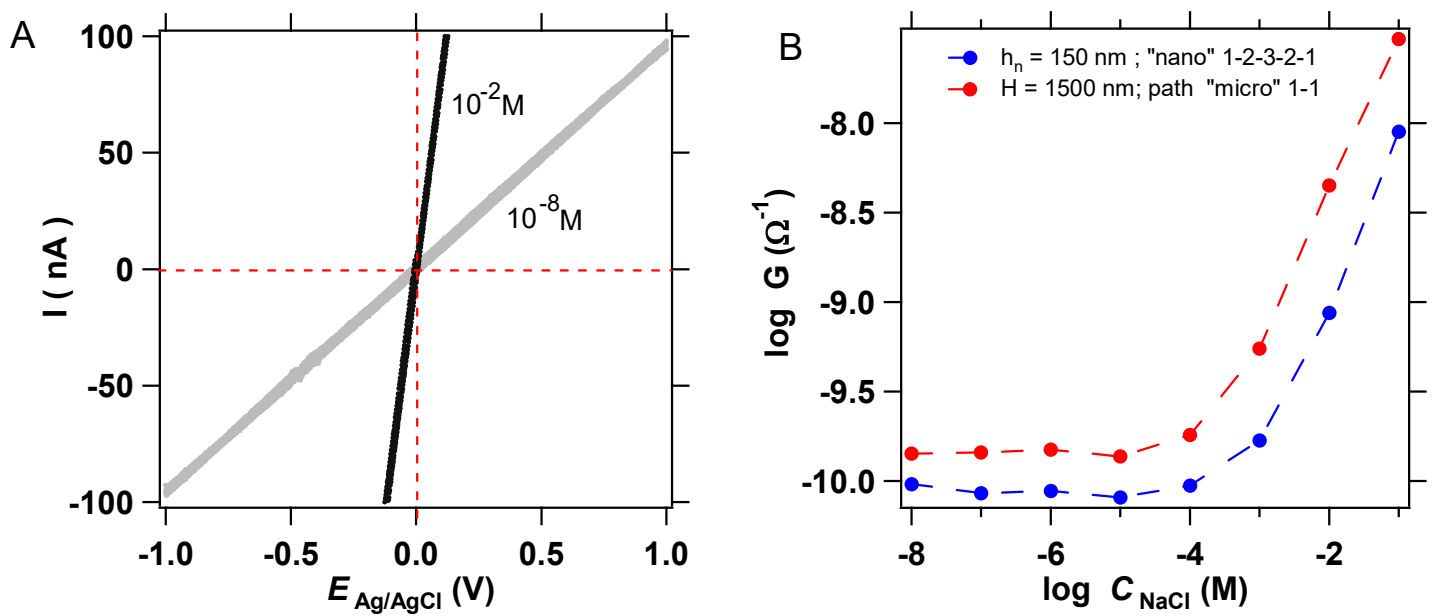

Figure 2. A. Measurement of the current flow variation plotted with potential range between -1 and $1 \mathrm{~V}$ in a $100 \mu \mathrm{m}$ width $\left(w_{\mathrm{n}}\right), 100 \mu \mathrm{m}$ length $\left(l_{\mathrm{n}}\right)$ nanoslit, and a $150 \mathrm{~nm}$ height $\left(h_{\mathrm{n}}\right)$ MNM device (see configuration Figure 1C) filled with BGE solution at two concentrations $\left(10^{-8}\right.$ and $\left.10^{-1} \mathrm{M}\right)$. B. Log-log scale representation of conductance change (slope changes in Figure 2B) with BGE concentrations through the nanoslit "1-2-3-2-3" path (see configuration Figure 1D (left)) and only throught the external branches "1-1" path (see configuration Figure 2D (right)). 


\section{Figure 3}

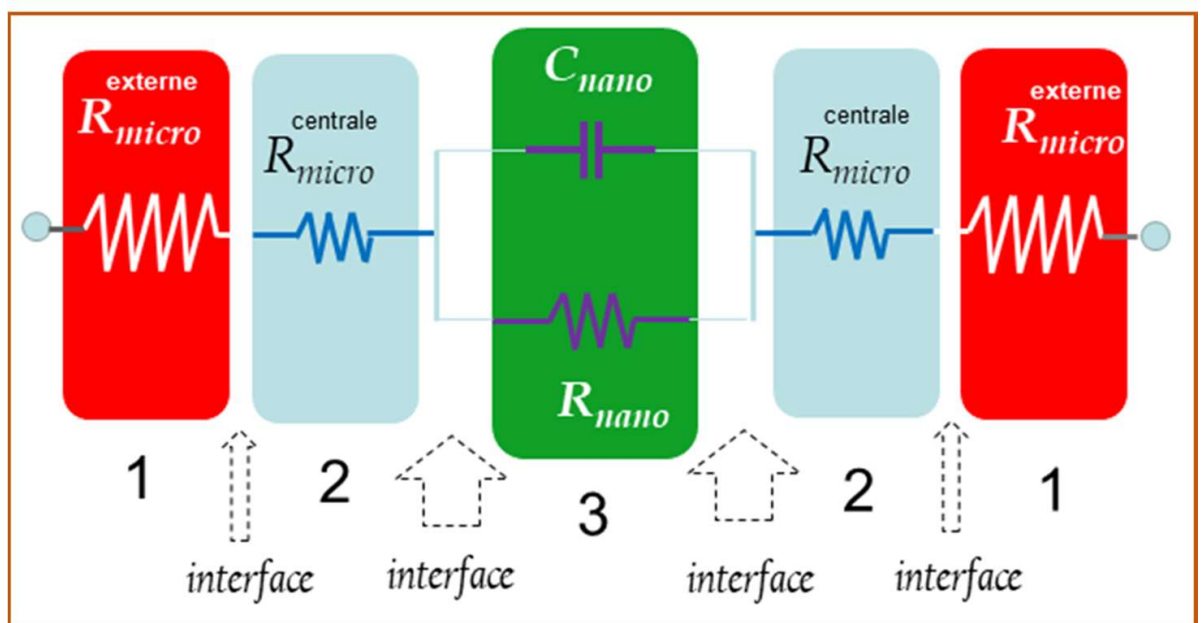

Figure 3. Equivalent electrical circuit of the MNM structure. Domain 1: global resistance in the external branches.

Domain 2: overall resistance in the central branches. Domain 3: Nanoslit is assimilated to an ionic filter where $C_{\text {nano }}$ corresponds to the geometric capacity associated in parallel with $R_{\text {nano }}$ corresponding to the overall nanoslit resistance of the nanoslit. 


\section{Figure 4}

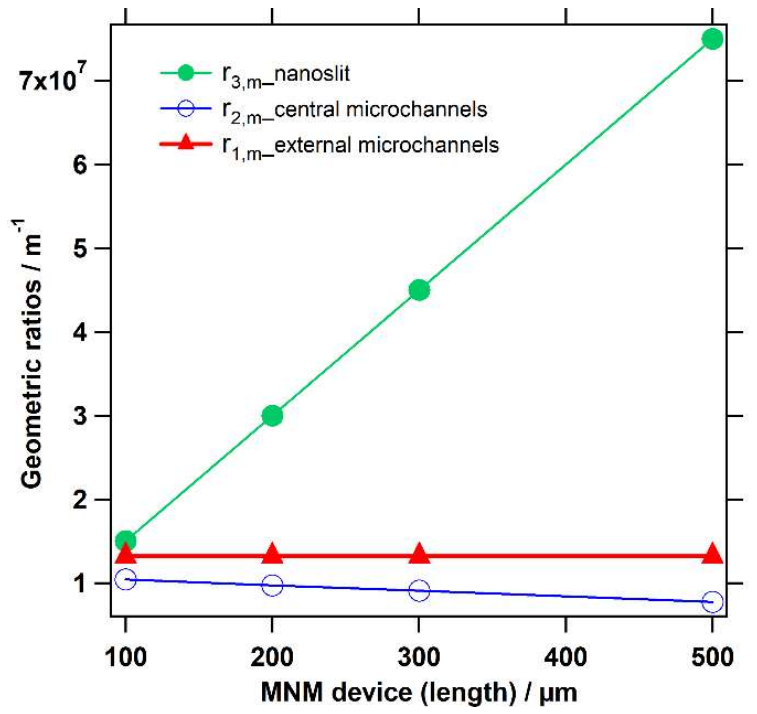

Figure 4. Straight lines variations of the ratio according to the nanoslit length for each MNM device where dimensions detailed in Table 1 and Figure 3 using Equations 16-18. 
Figure 5.
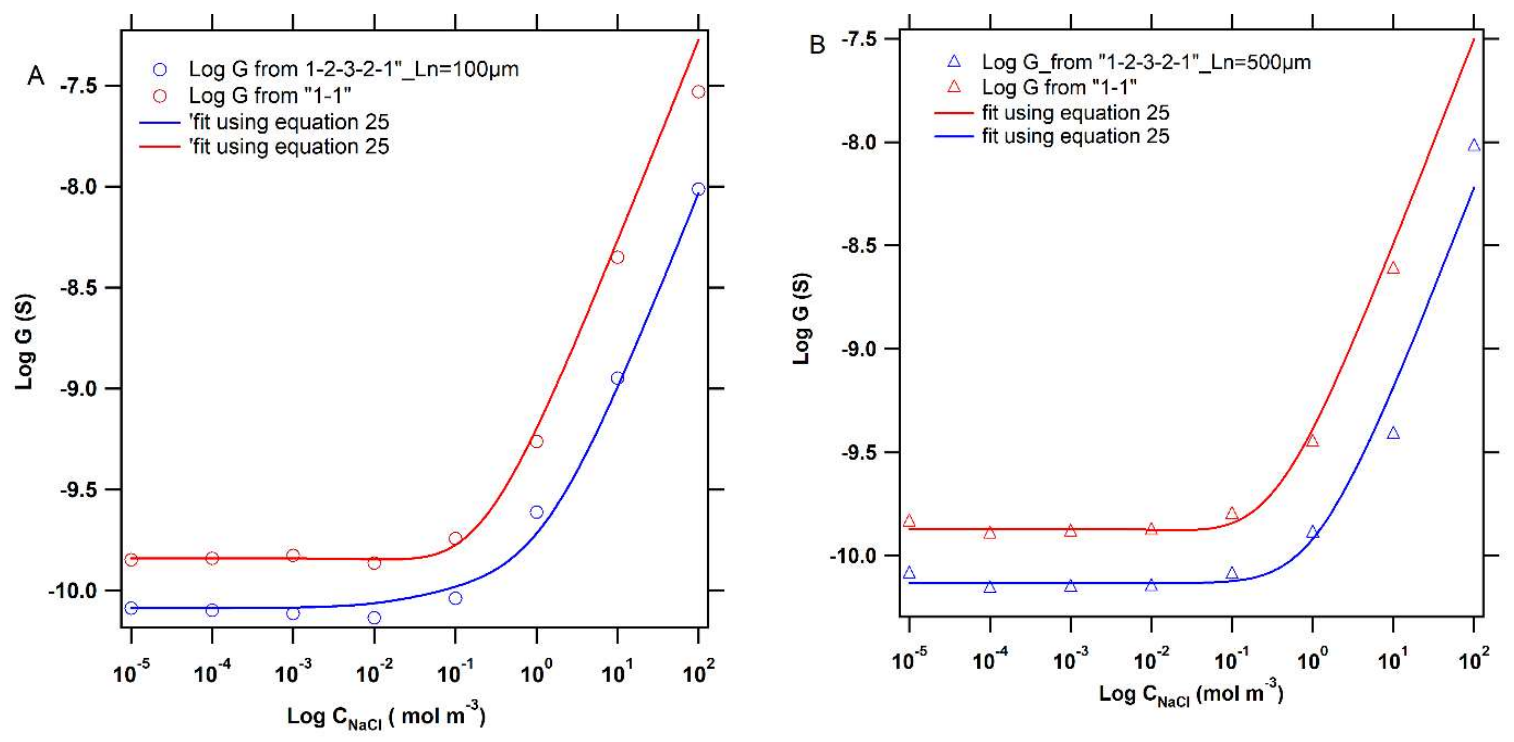

Figure 5. Experimental and fitted curves with the full model in Equation (25) tested for the "nano" and "micro" paths: A. $l_{\mathrm{n}}=100 \mu \mathrm{m}$ MNM device. B. $l_{\mathrm{n}}=500 \mu \mathrm{m}$ MNM device. 
Figure 6
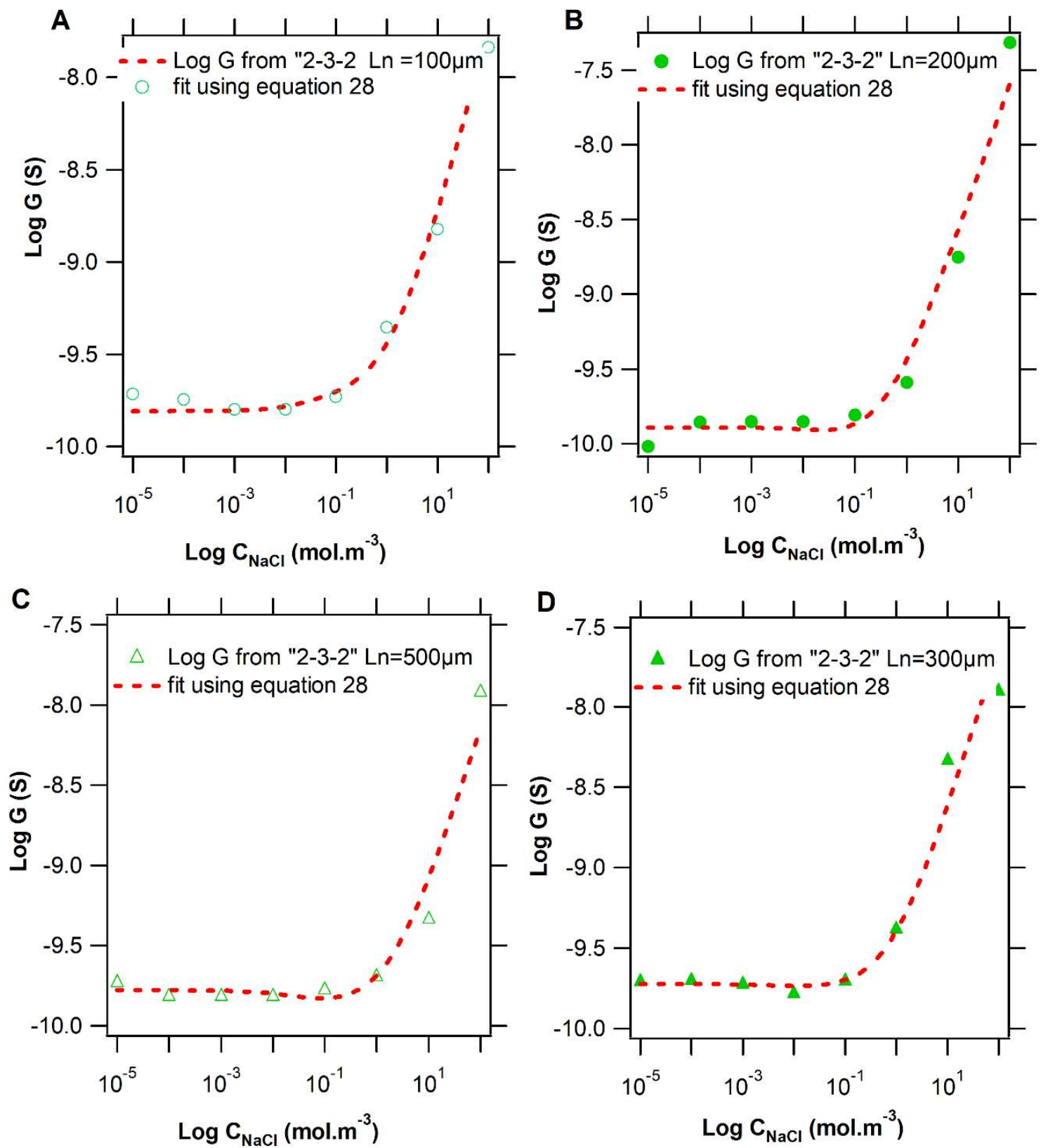
Figure 6. Experimental conductance curves "2-3-2" obtained after the eliminating procedure with Equations 28 and fitted conductance curves with the full model Equations 25 and 26 taking into account MNM i. e. only the central microchannels "2-2" directly connected with the nanoslit "3" (see Figure 1A and 3): A. $l_{\mathrm{n}}=100 \mu \mathrm{m}$ MNM device. B. $l_{\mathrm{n}}=200 \mu \mathrm{m}$ MNM device C. $l_{\mathrm{n}}=300 \mu \mathrm{m}$ MNM device D. $l_{\mathrm{n}}=500 \mu \mathrm{m}$ MNM device.

\section{Figure 7}

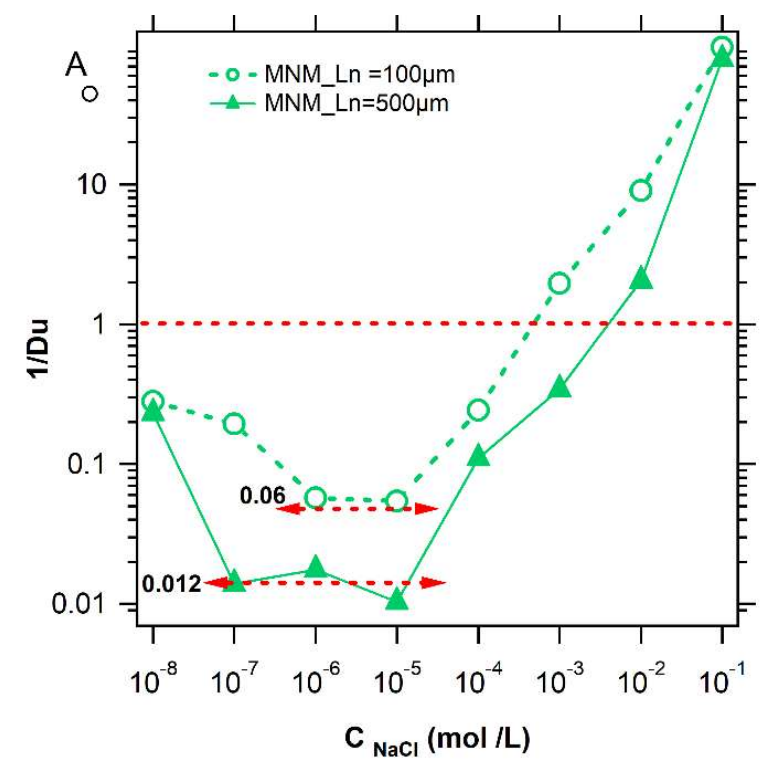

Figure 7. Experimental 1/Du curves obtained after the nondimensionalized procedure with the surface conductance $\mathrm{G}^{\mathrm{S}}$ taking into account only MNM (2-3-2) i. e. only the central microchannels "2-2" directly connected with the nanoslit "3" (see Figure 1A and 3) for $1_{n}=100 \mu \mathrm{m}$ MNM device and $1_{n}=500 \mu \mathrm{m}$ MNM device. 


\section{Figure 8}
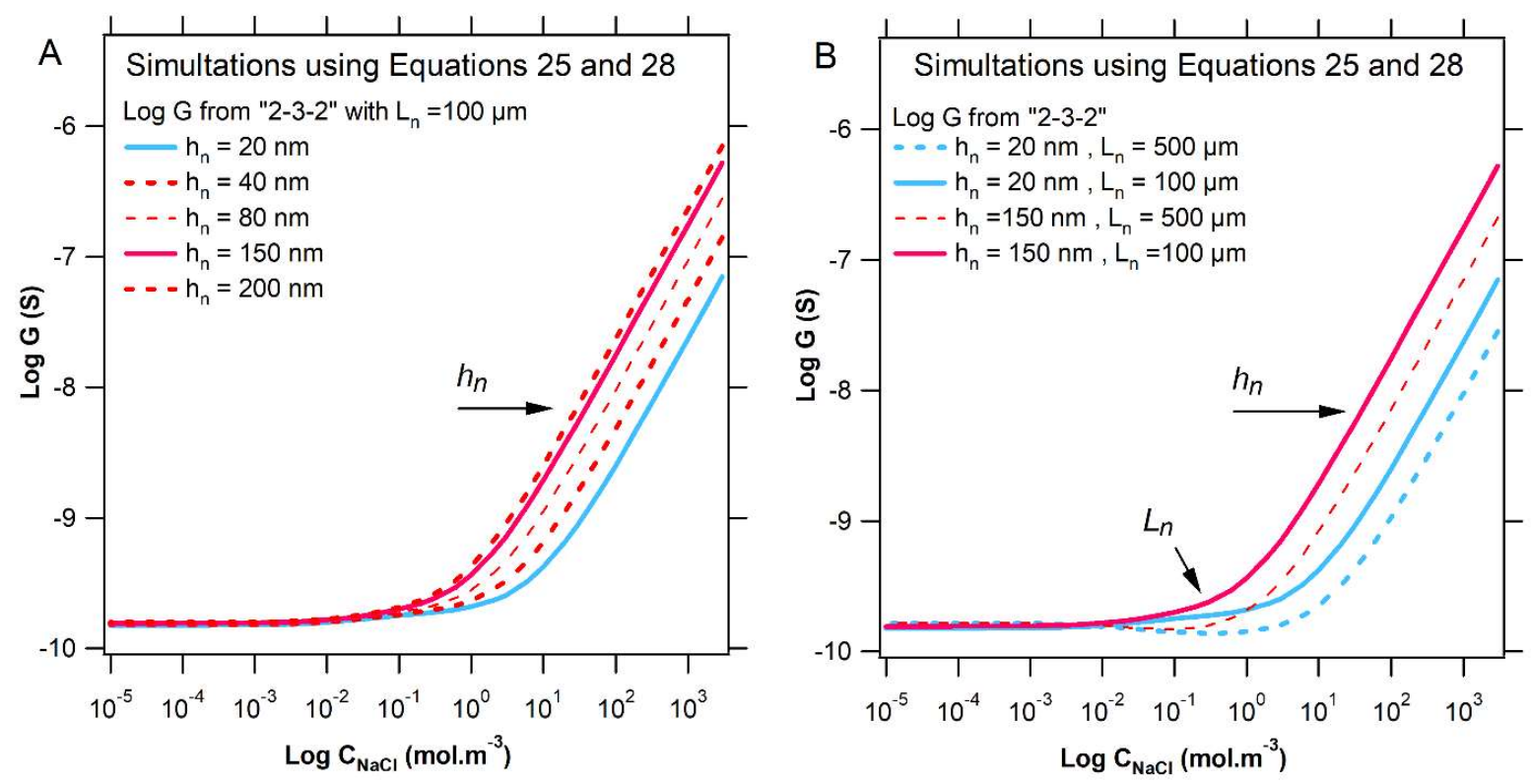

Figure 8. Simulating conductance curves "2-3-2" obtained after the simulation procedure with the improved model equations 25 and 28. All the parameters are locked to their theoretical expected values (see Table 3 ) except for $h_{\mathrm{n}}$ and $l_{\mathrm{n}}$. A. $h_{\mathrm{n}}$ variation from $200 \mathrm{~nm}$ to $20 \mathrm{~nm}$ with $l_{\mathrm{n}}=100 \mu \mathrm{m}$ fixed through the MNM device, and $\mathbf{B}$. Comparison between $l_{\mathrm{n}}=100 \mu \mathrm{m}$ and $500 \mu \mathrm{m}$ fixed with the two values of $h_{\mathrm{n}}(150 \mathrm{~nm}$ and $20 \mathrm{~nm})$. 